Case Report

\title{
Multiple Xanthogranulomas in an Adult Patient with Myelodysplastic Syndrome
}

\author{
Marta Martínez-García (iD, ${ }^{1}$ Nicolás Silvestre-Torner, ${ }^{1}$ \\ Antonio Aguilar-Martínez, ${ }^{1}$ and Fernando Burgos-Lázaro ${ }^{2}$ \\ ${ }^{1}$ Dermatology Service, Severo Ochoa University Hospital, Leganés, Madrid, Spain \\ ${ }^{2}$ Pathological Anatomy Service, Severo Ochoa University Hospital, Leganés, Madrid, Spain \\ Correspondence should be addressed to Marta Martínez-García; martamgml@yahoo.es
}

Received 7 September 2020; Accepted 25 November 2020; Published 7 December 2020

Academic Editor: Sergio A. Cuevas Covarrubias

Copyright (c) 2020 Marta Martínez-García et al. This is an open access article distributed under the Creative Commons Attribution License, which permits unrestricted use, distribution, and reproduction in any medium, provided the original work is properly cited.

\begin{abstract}
Adult multiple xanthogranuloma (XG) is a rare late-onset variant of juvenile XG. It is characterized by the appearance of papules or nodules located preferably on the trunk. A case of a 54-year-old man with myelodysplastic syndrome is presented as a history of interest, who consulted due to the appearance of multiple brownish papules distributed mainly in the trunk. So far, there are only 22 cases of this clinical form reported in the literature, 9 of them associated with malignant hematological processes. We highlight the importance of this entity as a possible cutaneous marker of blood dyscrasias.
\end{abstract}

\section{Introduction}

Xanthogranuloma (XG) is the most common form of clinical presentation of non-Langerhans cell histiocytosis. Although it can appear at any time of life, XG usually occurs in pediatric age and generally as a single lesion. The appearance of $\mathrm{XG}$ in adult patients is very rare and usually occurs in the form of multiple lesions. The association of XG with different blood dyscrasias has been documented both in the juvenile form and in the adult form, although in the latter in a more isolated way.

\section{Case Presentation}

A 54-year-old male came to the consultation with a 1-year history of clinical history indicating the appearance, spontaneously, of multiple skin lesions distributed on the trunk. The lesions showed a progressive increase in number and size and were not associated with local symptoms. In the personal history, the presence of a myelodysplastic syndrome with low-risk unilinear IPSS-R dysplasia, with an
IDH 1 mutation, diagnosed 3 years ago for which he maintained periodic control without treatment, stood out.

A dermatological examination revealed multiple papules between 3 and 5 millimeters in size, yellow-brown in color, distributed mainly in the trunk (Figure 1). The rest of the skin examination showed no data of interest. A histological study was performed that showed dermal occupation by mixed proliferation with elongated cells and multinucleated histiocytic-like cells of large eosinophilic cytoplasms with mild lymphocyte response. No significant atypia, mitosis, or necrosis was observed (Figure 2). The immunohistochemical study showed positivity for histiocytic markers CD 68 (Figure 3), vimentin (Figure 4), and alphal antitrypsin (Figure 5) and negativity for S-100, CD1a, factor XIIIa, and cytokeratins.

The hematological study carried out included bone marrow cytology with discrete hypocellularity with dysplasia in $39 \%$ of the granulocytic series. Nucleus-cytoplasmic maturation asynchrony was observed in the red series. No increase in the number of blasts was observed. In bone marrow cytometry, hypogranularity was observed in the 


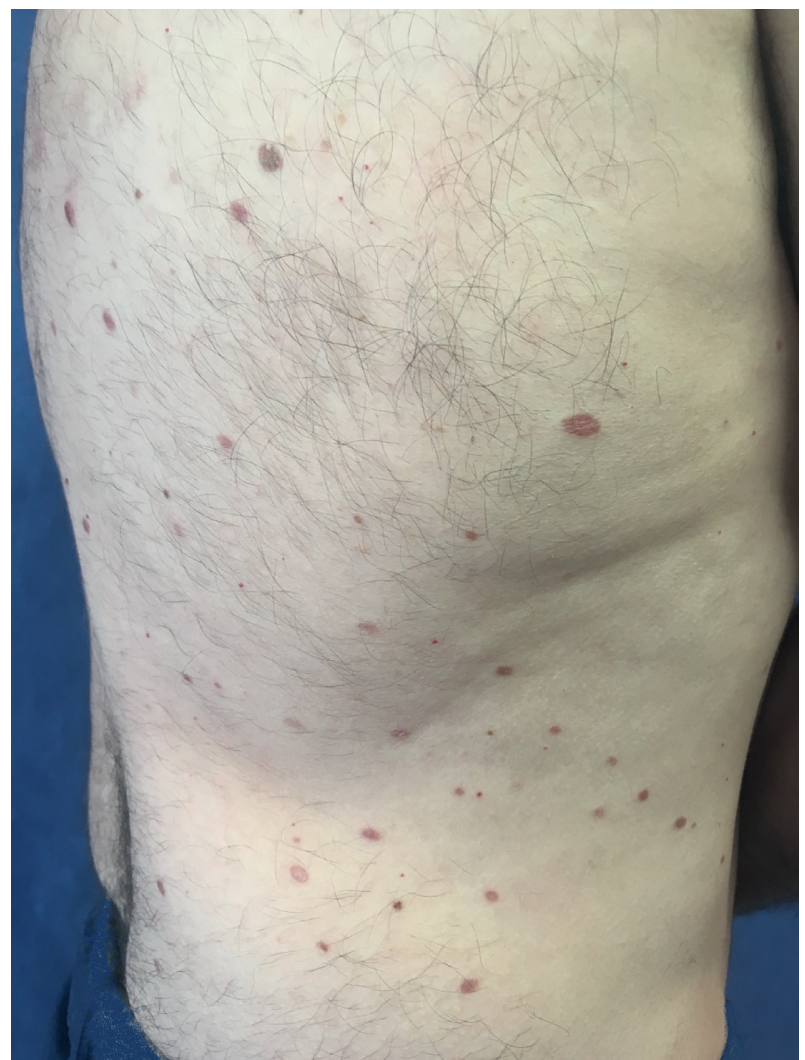

FIGURE 1: Multiple yellow-brown papules in the trunk.

granulocytic series without excess blasts. The following IDH1, TET2, and KMT2A mutations were found in the NGS molecular biology study.

The patient maintains periodic dermatological and hematological control. The skin lesions remained stable, and no type of treatment has been performed.

\section{Discussion}

XG usually appears in children, mainly in the first year of life, although it can appear at any time of life. The usual form of presentation is a single papule or nodule usually located on the head or neck. The appearance of XG in adults is infrequent, with only 22 cases described in the literature [1-8], being the usual presentation in these cases the multiple forms (10 or more lesions) that are preferably located on the trunk.

Histologically, the findings are similar in both the juvenile and adult forms [9]. A dense foam cell, giant cell, Touton cell, lymphocyte, and eosinophil infiltrate located at the level of the reticular dermis with extension to subcutaneous cell tissue are observed. Immunohistochemistry is positive for macrophage markers such as CD68, HAM56, and factor XIIIa. Negativity for CD 1a and S-100 allows them to be differentiated from Langerhans cell histiocytosis [10-12].

In most patients, $\mathrm{XG}$ lesions are located exclusively at the cutaneous level, but the presence of extracutaneous lesions have been described in both juvenile and adult forms [13], with the eyeball being the most frequently affected organ.

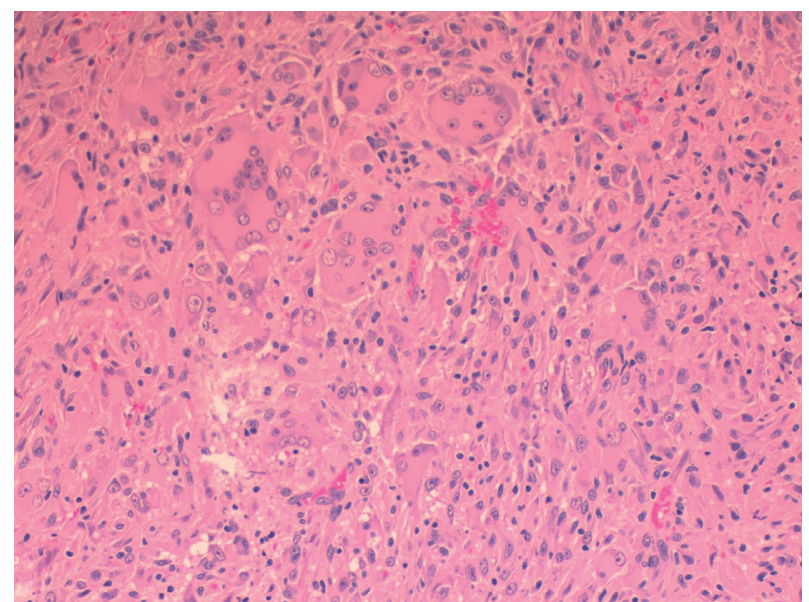

Figure 2: Mixed proliferation with elongated cells and multinucleated histiocytic-like cells of large eosinophilic cytoplasms with mild lymphocyte response $(\mathrm{H}-\mathrm{E} \times 20)$.

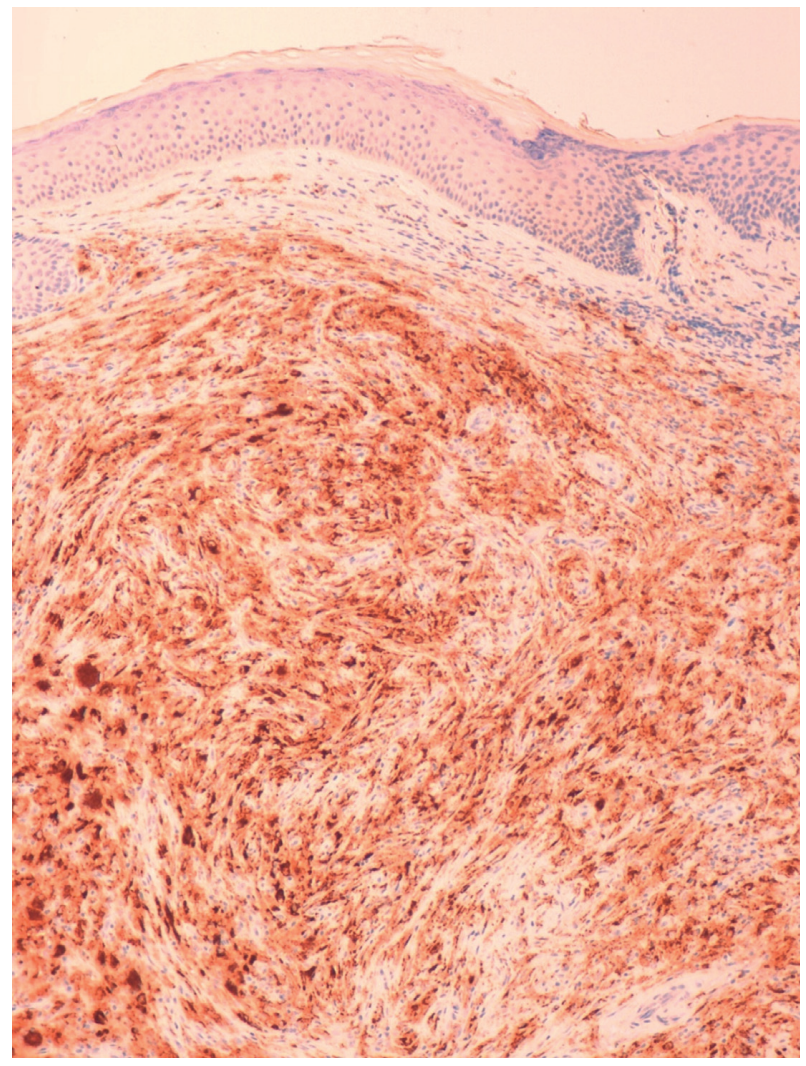

Figure 3: Positivity for histiocytic markers CD $68(\times 10)$.

The association between juvenile XG, neurofibromatosis type 1 , and chronic myeloid juvenile leukemia (CMJL) has been documented with approximately 20 patients reported in the literature [14]. A risk of developing CMJL of $0.4 \%-$ $1.6 \%$ has been estimated in children with neurofibromatosis type 1 and juvenile XG $[15,16]$.

In adult onset forms, association with blood dyscrasias has been described in a total of 9 patients and includes follicular lymphoma, essential thrombocytosis, chronic 


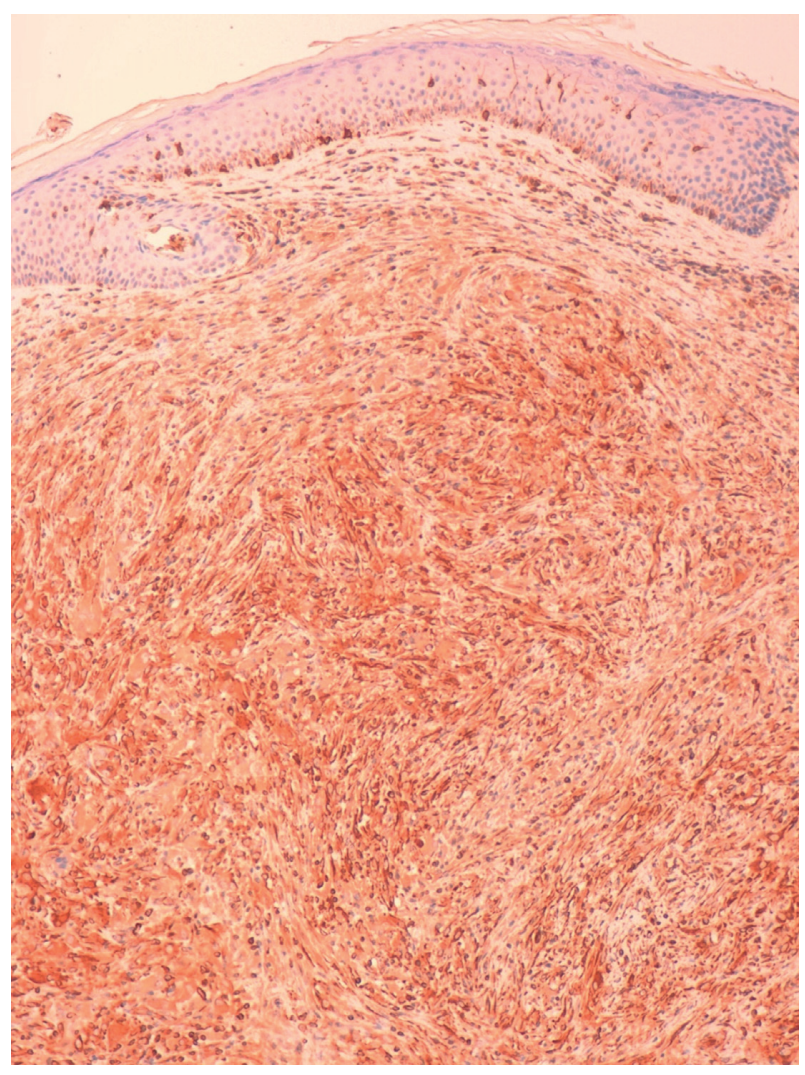

Figure 4: Positivity for vimentin $(\times 10)$.

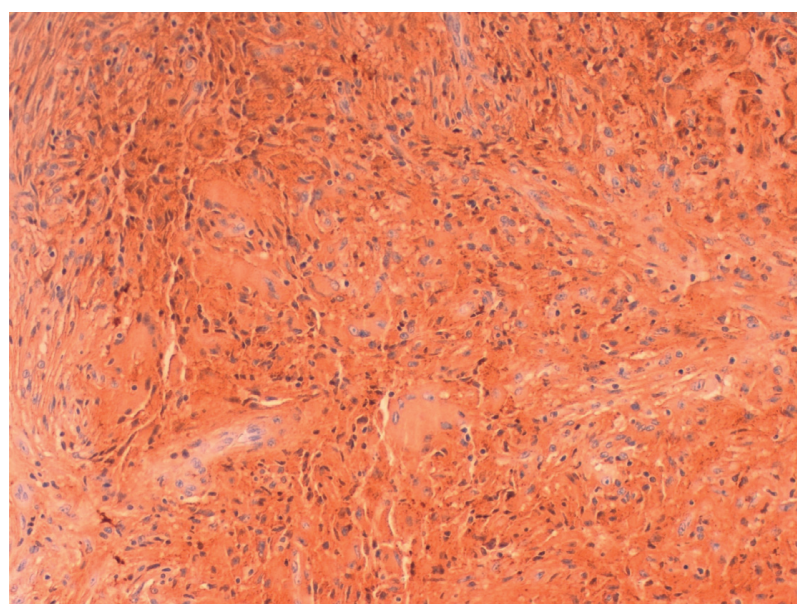

Figure 5: Positivity for alpha1 antitrypsin $(\times 20)$.

lymphatic leukemia B, acute lymphatic leukemia B, largecell lymphoma b, monoclonal gammopathy, adult $\mathrm{T}$ lymphoma/leukemia, and a single patient with myelodysplastic syndrome $[3,4,6-8,17,18]$. A case associated with a solid organ tumor has also been documented [19]. We must emphasize that all the patients presented multiple XG and that the development of the cutaneous lesions took place before, during, or after the hematological process. The etiopathogenic mechanism that would justify this association is unknown. Anomalous proliferation of histiocytes from a bone marrow CD 34+ precursor that would be activated against different stimuli such as the induction of cytokines or gammaglobulins produced by the underlying tumor process has been suggested $[4,6,20-22]$.

The evolution is usually towards spontaneous regression, less frequently in adults and in multiple forms [12]. In cases associated with blood dyscrasias, a tendency to regression has been observed when treating neoplasia [19]. There is no specific treatment for XG. In most cases, an expectant attitude is recommended, although $\mathrm{CO}_{2}$ laser, simple excision, and cryotherapy have been used.

Due to the low number of published cases, there is no agreement on the management of XG in adults, although it seems advisable to perform a physical examination together with a periodic hematological study.

In conclusion, we highlight the importance of recognizing these forms of multiple XG in adults as a possible marker of blood dyscrasias, describing a case of multiple XG in an adult patient associated with myelodysplastic syndrome.

\section{Data Availability}

No data were used to support this study.

\section{Conflicts of Interest}

The authors declare no conflicts of interest.

\section{References}

[1] N. Saad, F. Skowron, S. Dalle, J.-Y. Forestier, B. balme, and L. Thomas, "Multiple adult xanthogranuloma: case report and literature review," Dermatology, vol. 212, no. 1, pp. 73-76, 2006.

[2] A. Arun, B. Naskar, P. C. Mondal, and M. Pal, "Multiple generalised xanthogranuloma in adult: case report and treatment," Indian Journal of Dermatology, vol. 56, pp. 197199, 2011.

[3] B. Narváez-Moreno, Á. Pulpillo-Ruiz, T. De Zulueta-Dorado, and J. Conejo-Mir, "Disseminated juvenile xanthogranuloma associated with follicular lymphoma in an adult: successful treatment with chemotherapy and rituximab. A review of the literature," Actas Dermo-Sifiliográficas (English Edition), vol. 104, no. 3, pp. 242-246, 2013.

[4] C.-C. Chiou, P.-N. Wang, L.-C. Yang, T.-T. Kuo, and H.-S. Hong, "Disseminated xanthogranulomas associated with adult T-Cell leukaemia/lymphoma: a case report and review the association of haematologic malignancies," Journal of the European Academy of Dermatology and Venereology, vol. 21, pp. 532-535, 2007.

[5] P. Navajas, I. Eguino, O. Trébol, J. Lasa et al., "Multiple adul xanthogranuloma," Actas Dermosifiliogr, vol. 96, pp. 171-174, 2005.

[6] A. Biswas, B. Hamid, S. E. Coupland, A. Franks, and N. Leonard, "Multiple periocular adult onset xanthogranulomas in a patient with chronic lymphocytic leukaemia," European Journal of Dermatology, vol. 20, pp. 211-213, 2010.

[7] M. J. Larson, C. Bandel, P. J. Eichhorn, and P. D. Cruz Jr., "Concurrent development of eruptive xanthogranulomas and hematologic malignancy: two case reports," Journal of the American Academy of Dermatology, vol. 50, no. 6, pp. 976978, 2004. 
[8] G. M. Pino, F. J. Miquel, M. Velasco, J. J. Vilata, and A. Aliaga, "Multiple xanthogranulomas in an adult, associated with essential thrombocytosis," British Journal of Dermatology, vol. 132, pp. 1018-1021, 1995.

[9] S.-E. Chang, S. Cho, J.-C. Choi et al., "Clinicohistopathologic comparison of adult type and juvenile type xanthogranulomas in korea," The Journal of Dermatology, vol. 28, no. 8, pp. 413-418, 2001.

[10] A. Hernandez-Martin, E. Baselga, B. A. Drolet, and N. B. Esterly, "Juvenile xanthogranuloma," Journal of the American Academy of Dermatology, vol. 36, no. 3, pp. 355$367,1997$.

[11] M. W. Chang, "Update on juvenile xanthogranuloma: unusual cutaneous and systemic variants," Seminars in Cutaneous Medicine and Surgery, vol. 18, no. 3, pp. 195-205, 1999.

[12] L. P. Dehner, "Juvenile xanthogranulomas in the first two decades of life: a clinicopathologic study of 174 cases with cutaneous and extracutaneous manifestations," The American Journal of Surgical Pathology, vol. 27, no. 5, pp. 579-593, 2003.

[13] E. Cham, D. Siegel, and B. S. Ruben, "Cutaneous xanthogranulomas, hepatosplenomegaly, anemia, and thrombocytopenia as presenting signs of juvenile myelomonocytic leukemia," American Journal of Clinical Dermatology, vol. 11, no. 1, pp. 67-71, 2010.

[14] S. Paulus, S. Koronowska, and R. Fölster-Holst, "Association between juvenile myelomonocytic leukemia, juvenile xanthogranulomas and neurofibromatosis type 1: case report and review of the literature," Pediatric Dermatology, vol. 34, no. 2, pp. 114-118, 2017.

[15] W. H. C. Burgdorf and B. Zelger, "JXG, NF1, and JMML: alphabet soup or a clinical issue?" Pediatric Dermatology, vol. 21, no. 2, pp. 174-176, 2004.

[16] A. Zvulunov, Y. Barak, and A. Metzker, "Juvenile xanthogranuloma, neurofibromatosis, and juvenile chronic myelogenous leukemia: world statistical analysis," Archives of Dermatology, vol. 131, no. 8, pp. 904-908, 1995.

[17] T. Namiki, K. Miura, and H. Yokozeki, "Multiple CD163+adult xanthogranuloma associated with myelodysplastic syndrome," The Journal of Dermatology, vol. 42, no. 11, pp. 1106-1107, 2015.

[18] B. A. Shoo, K. Shinkai, T. H. McCalmont, and L. P. Fox, "Xanthogranulomas associated with hematologic malignancy in adulthood," Journal of the American Academy of Dermatology, vol. 59, no. 3, pp. 488-493, 2008.

[19] S. Vadeboncoeur and N. Provost, "Multiple xanthogranulomas in an adult: known entity, new association," Journal of Cutaneous Medicine and Surgery, vol. 20, no. 5, pp. 474-477, 2016.

[20] H. Sueki, T. Saito, M. Iijima, and R. Fujisawa, "Adult-onset xanthogranuloma appearing symmetrically on the ear lobes," Journal of the American Academy of Dermatology, vol. 32, no. 2, pp. 372-374, 1995.

[21] H. H. Balfour, C. E. Speicher, D. G. McReynolds, and M. E. Nesbit, "Juvenile xanthogranuloma associated with cytomegalovirus infection," The American Journal of Medicine, vol. 50, no. 3, pp. 380-384, 1971.

[22] S. Pérez-Gala, A. Torrelo, I. Colmenero, T. Contra, L. Madero, and A. Zambrano, "Juvenile multiple xanthogranuloma in a patient with Langerhans cell histiocytosis," Actas DermoSifiliográficas, vol. 97, no. 9, pp. 594-598, 2006. 